\title{
Platelet lysates in Hepatocellular Carcinoma patients after radiofrequency ablation facilitate tumor proliferation, invasion and vasculogenic mimicry
}

\author{
Guoqun Jia*, Jian Kong*, Changyu Yao, Shilun Wu, Wenbing Sun ${ }^{\bowtie}$ \\ Department of Hepatobiliary Surgery, Beijing Chao-yang Hospital, Capital Medical University, Beijing, China. \\ *These authors contributed equally to the work. \\ $\triangle$ Corresponding author: Wenbing Sun, Department of Hepatobiliary Surgery, Beijing Chao-yang Hospital, Capital Medical University, No. 5 Jingyuan Road, \\ Shijingshan District, Beijing 100043, China, E-email: sunwenbing@bjcyh.com, Tel.: +86-010-51718382, Fax: +86-010-51718372. \\ (c) The author(s). This is an open access article distributed under the terms of the Creative Commons Attribution License (https://creativecommons.org/licenses/by/4.0/). \\ See http://ivyspring.com/terms for full terms and conditions.
}

Received: 2020.01.30; Accepted: 2020.07.06; Published: 2020.07.29

\begin{abstract}
Background: Platelets play important roles in tumorigenesis, angiogenesis and metastatic dissemination of tumor cells. Radiofrequency ablation (RFA) could increase the circulating tumor cells in patients with primary or metastatic lung tumors. Whether platelet lysates in hepatocellular carcinoma (HCC) after RFA promote tumor progression has not been elaborated.

Methods: HCC patients within Milan Criteria and without taking anti-platelet drugs were selected in the study. MTT assay, colony formation assay, transwell assay, tube formation and western blot were used to evaluate the effect of platelet lysates on HCC cells in vitro. Lung metastatic assay was performed in vivo.

Results: Platelet lysates from patients after RFA promoted cell proliferation, colony formation, migration, invasion and vasculogenic mimicry in Hep3B and HCCLM3 cells compared with those from patients before RFA. Platelet lysates after RFA significantly increased the expression of p-Akt, p-Smad3 and snail, and decreased the expression of E-cadherin compared with those before RFA in Hep3B and HCCLM3 cells. Hep3B-Luc2-tdT cells incubation with platelet lysates from patients after RFA displayed enhanced lung metastasis compared with those before RFA.

Conclusions: Platelet lysates from HCC patients after RFA promoted the proliferation, migration, invasion and vasculogenic mimicry of HCC cells, which indicated that RFA in combination with anti-platelet drug may be used to improve the prognosis of HCC.
\end{abstract}

Key words: Platelets; Hepatocellular carcinoma; Radiofrequency ablation; Metastasis; Vasculogenic mimicry

\section{Introduction}

Hepatocellular carcinoma (HCC) is a major cause of cancer-related mortality worldwide [1]. Ablative therapies, in particular, radiofrequency ablation (RFA) are commonly considered a curative option for patients whose tumors are not amenable to resection [2]. The recurrence rate of HCC within Milan criteria undergoing RFA is $8-26 \%$ in three years [3]. Furthermore, tumor progression including rapid growth or metastasis in HCC after RFA could happen.

Platelets play important roles in tumorigenesis, contributing to inflammation, angiogenesis and metastatic dissemination of tumor cells [4]. Circulating platelets contain numerous proteins, including growth factors, chemokines and proteases, which are synthesized by megakaryocytes or absorbed from the blood by the platelets themselves [5]. Platelets may become activated systemically or within the tumor, potentially resulting in release of platelet content into the circulation [6]. Up to $40 \%$ of HCC patients have portal vein thrombosis at time of diagnosis, which indicated platelets are activated in HCC [7]. The aggregation of blood platelets around cancer cells protect these cells from the immune system and facilitate their circulation in the bloodstream and their adhesion at potential sites of metastasis [8]. In addition, tumor-associated platelets 
can release several permeability factors and enzymes that assist metastatic tumor cells to engraft at distant sites [9].

RFA induced tumor cell dissemination in patients with colorectal liver metastases [10]. RFA also increased the circulating tumor cells in patients with primary or metastatic lung tumors [11]. Radiofrequency catheter ablation has become standard treatment for the cure and prevention of atrial fibrillation [12]. However, thromboembolic events could occur as a complication of the procedure. RFA could indeed favor intra-atrial thrombogenesis through activation of the coagulation cascade related to both catheter placement- and radiofrequencyinduced tissue injury. Importantly, platelet activation consequent to atrial endocardial injury likely also plays a significant role in initiating the mechanisms eventually leading to thrombosis [13]. However, whether platelets in HCC after RFA promote tumor progression has not been elaborated. In contrast to the heterogeneity displayed by tumor cells, platelets are relatively invariable, and targeting them is potentially, promising method of inhibiting metastasis.

In the present study, we compared the effect of platelet lysates before and after RFA on HCC cell lines. We found that platelet lysates from HCC patients after RFA could promote the proliferation, migration, invasion and vasculogenic mimicry of HCC cells. Furthermore, platelet lysates from patients after RFA accelerated lung metastasis of HCC cells. Combination of RFA and anti-platelet drug may be used to prevent HCC local recurrence and metastasis.

\section{Materials and Methods}

\section{Patient selection}

The study was approved by the ethical committee of Beijing Chao-yang Hospital, the approval number was 2015-科-28, and the need to obtain written informed consent was waived. HCC patients within Milan Criteria and without other severe and serious organ disease, taking anti-platelet drugs and receiving chemotherapy or interventional therapy in our hospital were selected in the study. Milan criteria were defined as one tumor $\leq 5 \mathrm{~cm}$, or two or three tumors with each tumor $\leq 3 \mathrm{~cm}$ without any vascular invasion or metastasis as observed by computed tomography.

\section{Blood samples}

In each patient, $5 \mathrm{ml}$ blood samples were collected before RFA and 24 hours after RFA. Blood from patients was drawn directly into two plastic tubes containing $3.8 \%$ buffered sodium citrate.
Samples were spun at $200 \mathrm{~g}$ for $15 \mathrm{~min}$ at ambient temperature to obtain platelet-rich plasma (PRP). The PRP was transferred to a clean tube and recentrifuged (500 $\mathrm{g}$ for $15 \mathrm{~min}$ at ambient temperature). The platelet was used to evaluate the effect of platelet lysates on HCC cell in vitro and in vivo.

\section{Antibodies}

Horseradish peroxidase (HRP)-labeled antimouse and anti-rabbit secondary antibodies were from MBL (Nogaya, JPN). Phospho-anti-Akt, pERK1/2, p-Smad3, anti-E-cadherin, snail, ERK2, Akt, and Smad3 antibodies were purchased from Cell signaling (Beverly, CA, USA). Anti- $\beta$-actin were bought from Abcam (Cambridge, TX, USA).

\section{Cells}

The human HCC cell line Hep3B, Hep3B-Luc2tdT and HCCLM3 cells were obtained from the National Infrastructure of Cell Line Resource (Beijing, China). Cells were cultured in high-glucose Dulbecco's modified Eagle medium (DMEM) supplement with $10 \%$ fetal bovine serum (FBS), $100 \mathrm{U} / \mathrm{ml}$ penicillin and $100 \mu \mathrm{g} / \mathrm{ml}$ streptomycin in humidified atmosphere of $5 \% \mathrm{CO}_{2}$ at $37^{\circ} \mathrm{C}$.

\section{Platelet lysates}

Platelets were collected from HCC patients within Milan criteria before and after RFA. The platelets were subjected to several freeze-thaw cycles to disrupt their membranes and release the growth factors stored in the granules in order to acquire the platelet lysates. During the procedure of experiments, the number of platelet used to obtain platelet lysates was 100 times the number of HCC cells. HCC cells were co-cultured with equivalent volume of platelet lysates for the following experiments.

\section{Cell viability assay}

Hep3B or HCCLM3 cells were trypsinzed and seeded into 96-well plates at a density of approximately $3 \times 10^{3}$ cells per well. After $24 \mathrm{~h}$, adherent cells were treated with platelet lysates. After $24 \mathrm{~h}, 48 \mathrm{~h}$ and $72 \mathrm{~h}$ incubation, MTT reagent was added to the cells $(0.5 \mathrm{mg} / \mathrm{ml})$, and cells were then incubated for $4 \mathrm{~h}$ at $37^{\circ} \mathrm{C}$. The cells media were removed and $150 \mu \mathrm{l}$ DMSO were added to each well followed by gentle shaking of the plates to dissolve the formazan crystals. The optical density (OD) was then measured using an automated ELISA plate reader at $570 \mathrm{~nm}$.

\section{Colony formation assay}

Briefly, 6-well dishes were seeded with $1 \times 10^{3}$ viable cells and allowed to grow for $24 \mathrm{~h}$. The cells were then incubated in the presence of platelet lysates 
in DMEM with 2\% FBS for 2 weeks. The colonies obtained were washed with PBS, fixed in $4 \%$ paraformaldehyde for $20 \mathrm{~min}$ at room temperature and then washed with PBS followed by staining with crystal violet.

\section{Western blot}

HCC cells were collected and cell lysis was performed by using RIPA lysis buffer including protease and phosphatase inhibitors on ice. The extracted protein was quantified by bicinchoninic acid quantification assay. Then, the total cellular proteins were subjected to SDS-PAGE gel and transferred to nitrocellulose membranes. The membranes were blocked with $5 \%$ non-fat milk for $1.5 \mathrm{~h}$ and then incubated with respective primary antibody overnight at $4^{\circ} \mathrm{C}$. Following washing three times with TBST for $10 \mathrm{~min}$, the membranes were incubated with the appropriate HRP-conjugated secondary antibody for $1.5 \mathrm{~h}$ at room temperature. The bands were captured with SuperSignal West Pico substrate (Thermo scientific, Rockford, IL, USA).

\section{Migration and invasion assay}

Cell migration assays were operated by a modified Boyden chamber (Costar-Corning, New York, USA). Hep3B or HCCLM3 cells $\left(2 \times 10^{4}\right.$ cells per well) and platelet lysates were added into the upper chamber, and $600 \mu \mathrm{L}$ DMEM with $10 \%$ FBS were added into the lower chamber. The chambers were incubated for $24 \mathrm{~h}$. After removing the filter inserts and the cells on the upper side of the filter, the migrated cells on the lower chamber were stained with crystal violet for 20 min, washed with PBS, and captured. Migration was assessed by counting the number of stained cells from 5 random fields.

For cell invasion assay, each insert needed was precoated with Matrigel. The others steps were similar to cell migration assay.

\section{Tube formation assay}

Growth factor-reduced Matrigel $(10 \mathrm{mg} / \mathrm{ml} ; \mathrm{BD}$ Biosciences) was thawed overnight at $4^{\circ} \mathrm{C}$, and $70 \mu \mathrm{l}$ was added to each well of a 96-well plate and allowed to solidify for $30 \mathrm{~min}$ at $37^{\circ} \mathrm{C}$. Hep3B or HCCLM3 cells $\left(2 \times 10^{4}\right)$ were incubated with platelet lysates for $4 \mathrm{~h}$. Capillary tube formation was observed. Total length and number of junctions of the tubes were quantified using Image software and the Angiogenesis Analyzer plugin of the capillary-like structures.

\section{Lung metastatic assay}

Hep3B-Luc2-tdT cells were treated with platelet lysates for $24 \mathrm{~h}$, and cells $\left(1 \times 10^{6}\right.$ cells) were collected, suspended in $100 \mu \mathrm{l}$ PBS and injected through tail vein. Three weeks after the injection, the mice were sacrificed and the lung tissues were isolated for in vivo Imaging System (Carestream Health, Inc.). The number of visible tumors on lung surface was counted.

\section{Statistical analysis}

All values are expressed as the mean \pm SD. The data were analyzed using Student's $t$ test or the ANOVA test. A $P$ value of $<0.05$ was considered statistically significant. GraphPad Prism8 (GraphPad Software Inc., San Diego, California, USA) was used for these analyses.

\section{Results}

\section{Platelet lysates from patients after RFA promote cell proliferation, colony formation, migration and invasion in HCC cells}

We selected patients within Milan Criteria, acquired the platelet lysates before and after RFA, and examined the effect of platelet lysates on HCC cells proliferation, migration and invasion. The characteristic of patients were shown in Table S1. MTT assay and colony formation assay were used to observe the effect of platelet lysates on HCC cell proliferation. Hep3B and HCCLM3 cells after incubation with platelet lysates from patients after RFA displayed increased proliferation and colony formation ability compared with those before RFA (Figure 1). We also evaluate the effect of platelet lysates on HCC cell migration and invasion using transwell assay. Platelet lysates from patients after RFA significantly promoted cell migration and invasion of Hep3B and HCCLM3 cells compared with those before RFA (Figure 2).

\section{Platelet lysates from patients after RFA facilitate vasculogenic mimicry of HCC cells}

To examine the effect of platelet lysates on vasculogenic mimicry, tube formation assay was used. Hep3B and HCCLM3 cells after incubation with platelet lysates from patients after RFA formed more tubes compared with those from before RFA (Figure 3). These data indicated that platelet lysates from patients after RFA were more likely to promote vasculogenic mimicry channels of HCC cells.

\section{Platelet lysates after RFA may activate epithelial mesenchymal transition of HCC through Akt, ERK1/2 and Smad3 signaling pathways}

We also investigated the associated mechanism involved in the process. We collected 5 pair cases of platelets and observed the effect of platelet lysates. Platelet lysates from patients after RFA significantly increased the expression of p-Akt, and snail, and 
decreased the expression of E-cadherin compared with those before RFA in Hep3B and HCCLM3 cells (Figure $4 \mathrm{~A}, \mathrm{~B}$ and E). The expression of p-ERK1/2 was upregulated after treatment with platelet lysates after RFA compared with those before RFA in HCCLM3 cells (Figure 4B and E). Platelet lysates form patients after RFA also upregulated the expression of p-Smad3 compared those before RFA in Hep3B and HCCLM3 cells (Figure 4C, D and F).

We further used the ERK1/2 signaling inhibitor (U0126), PI3K signaling inhibitor (LY297002) and TGF- $\beta$ signaling inhibitor (SB431542) to treat Hep3B and HCCLM3 cells before platelet lysates were added. Platelet lysates after RFA promoted the proliferation, migration, and tube formation of Hep3B and HCCLM3 cells compared with those before RFA, and U0126, LY294002 and SB431542 partly suppressed the effect of platelet lysates after RFA (Supplementary Figure 1-3). Furthermore, pretreated with U0126, LY294002 or TGF- $\beta$, Hep3B and HCCLM3 cells still showed faster proliferation treated with platelet lysates after RFA compared with platelet lysates before RFA (Supplementary Figure 1-3). The results showed that ERK1/2, PI3K and TGF- $\beta$ signaling pathways may be involved in the process of platelet lysates promoting proliferation, migration and vasculogenic mimicry of HCC cells.

\section{Platelet lysates from patients after RFA promote lung metastasis of HCC cells}

Furthermore, we determined the effects of platelet lysates on the metastasis of HCC cells by in vivo Imaging System to quantify metastatic nodules. The number of metastatic nodules was increased in mice injected with Hep3B-Luc2-tdT cells after treatment with platelet lysates from patients after RFA compared with those injected with Hep3B-Luc2tdT cells after treatment with platelet lysates from patients before RFA (Figure 5A and B). There were no apparent changes in body weight in the two groups (Figure 5C).

\section{Discussion}

Platelets have been recognized as key player in the regulation of tumor metastasis and angiogenesis [14]. In the present study, platelet lysates from HCC patients after RFA could promote the proliferation, migration, invasion and vasculogenic mimicry of HCC cells, which indicated that anti-platelet therapy may prevent recurrence and metastasis in HCC after RFA.
A

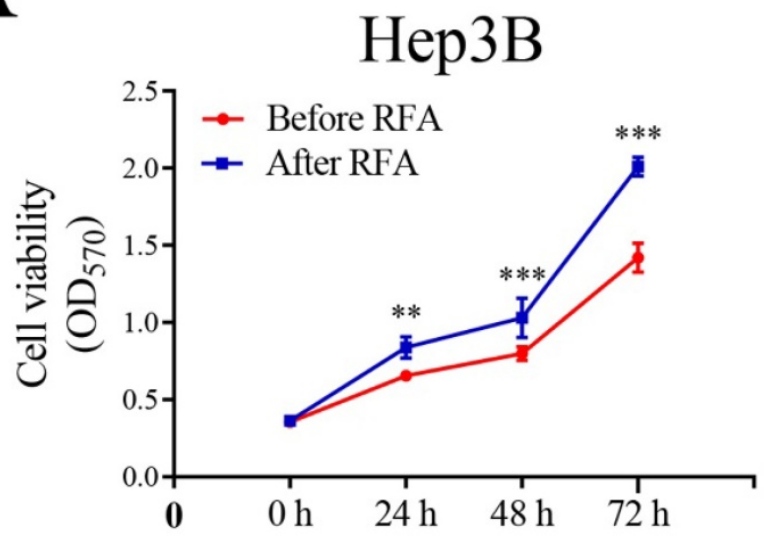

$\mathrm{B}$

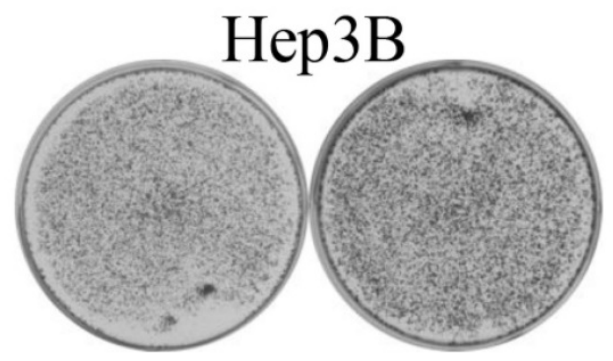

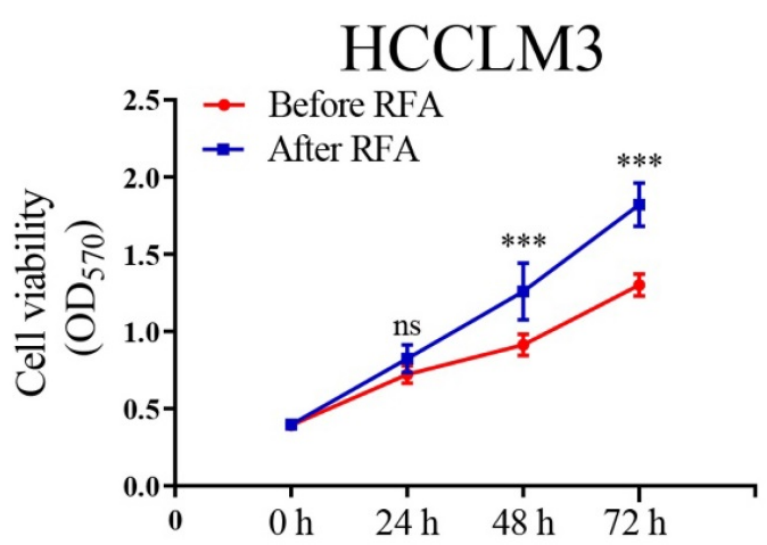

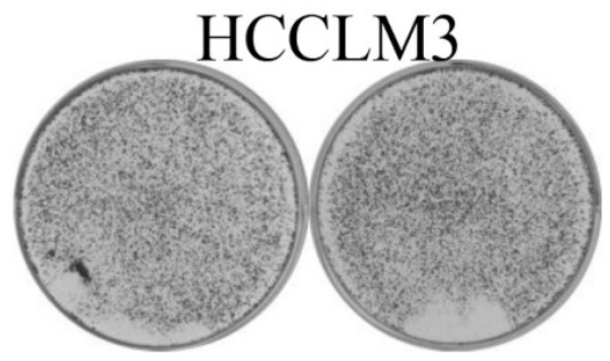

Figure 1. Platelet lysates from patients after RFA promote cell proliferation and colony formation of HCC cells. We selected HCC patients within Milan Criteria, acquired the platelet lysates before and after RFA, and examined the effect of platelet lysates on HCC cells proliferation. (A) Hep3B and HCCLM3 cells were seeded at $3 \times 10^{3}$ cell per well into a 96 -well plate, and incubated with platelet lysates. On $24 \mathrm{~h}, 48 \mathrm{~h}$ and $72 \mathrm{~h}$, MTT was added and OD was measured. (B) Hep3B and HCCLM3 were seeded at $1 \times 10^{3}$ cells per well into a 6 -well plate, and incubated with platelet lysates. On 14 days, cells were stained with crystal violet. Data are presented as mean \pm SD. ns: no significance; ** $P<0.01 ;{ }^{* * * * *} P<0.001 ;$ ns, no significance. 
A

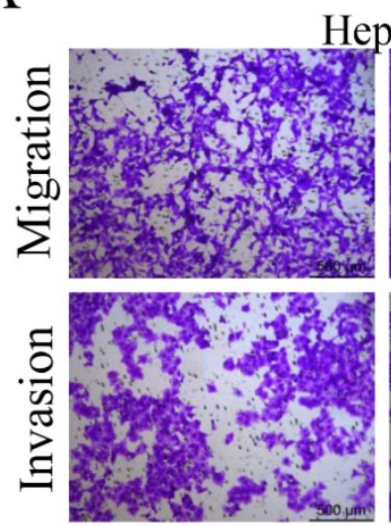

Before RFA
Hep3B

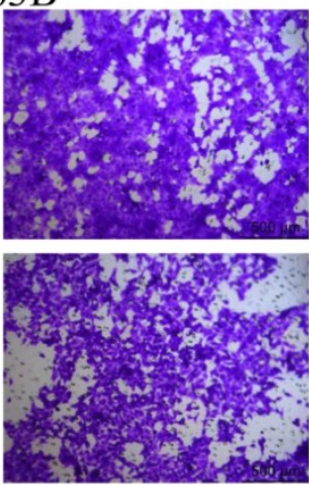

After RFA

B
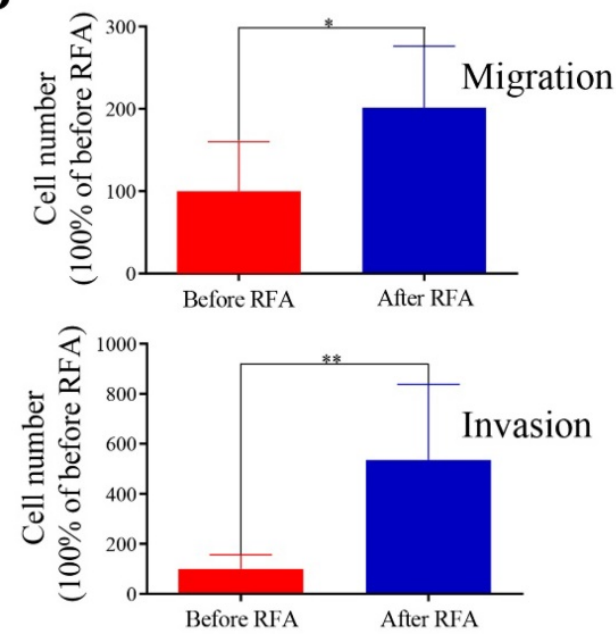

D

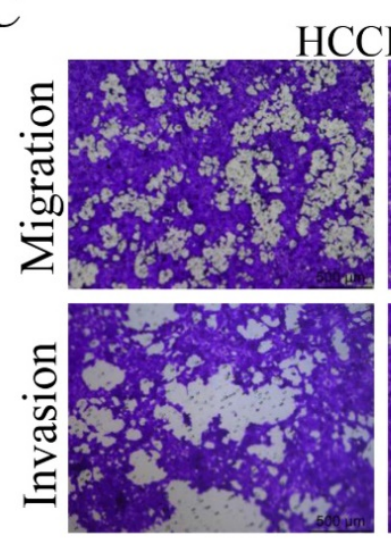

Before RFA
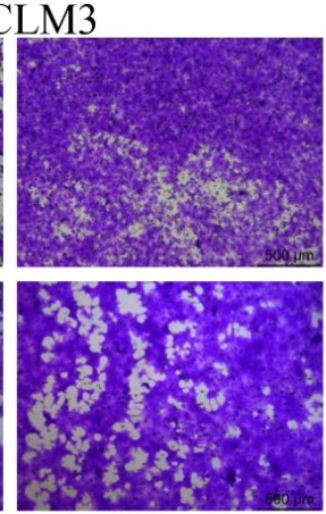

After RFA
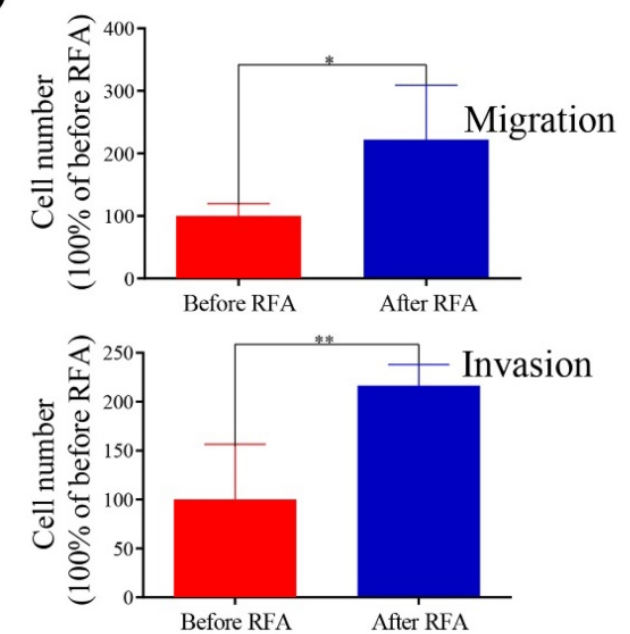

Figure 2. Platelet lysates from patients after RFA accelerate cell migration and invasion in HCC cells. Transwell assay was used to examine the effect of platelet lysates on HCC cells migration and invasion. Hep3B and HCCLM3 cells were seeded into the upper chamber, and incubated with platelet lysates. On $24 \mathrm{~h}$ or $48 \mathrm{~h}$, migrating or invading tumor cells were examined. (A, C) Representative migration and invasion of HCC cells treated with platelet lysates from patients before or after RFA in Hep3B and HCCLM3 cells. (B, D) Quantification of tumor cell migration and invasion is shown in Hep3B cells and HCCLM3 cells. Data are presented as mean \pm SD. ${ }^{*} P<0.05$; ${ }^{*} P<0.01$.

Increased platelet activation has been reported in many types of cancer, and activated platelets participate in the progression of the tumor [15-17]. Following activation, platelets release extracellular vesicles and granule containing exosomes, microparticles and pro-angiogenic protein, which promote tumor growth, metastasis and angiogenesis. In the field of HCC and platelets most researches focused on the prognostic role of platelet to lymphocyte radio or platelet count in HCC [18]. One study demonstrated that no differences in the basal and agonist induced platelets activation status between patients with or without HCC [19]. However, another study suggested that anti-platelet therapy could prevent hepatitis B virus-associated HCC [20]. Platelets extracts also decreased doxorubicin-mediated growth inhibition and apoptosis induction in HCC cells [21]. Platelet extracts induced growth, migration and invasion in HCC in vitro [22]. Platelet releases promoted the proliferation of HCC cells by suppressing the expression of KLF6 [23]. In our study, we found that platelet lysates from HCC patients after RFA could promote proliferation, colony formation, migration and invasion in vitro, which indicated that antiplatelet therapy may be used to prevent the progression of HCC after RFA.

Vasculogenic mimicry is a novel paradigm of tumor perfusion supported by tumor cells instead of traditional endothelial cells [24]. Vasculogenic mimicry functions as a route for metastatic dissemination of tumor cells and is associated with tumor cell migration and invasion, which indicates tumor metastasis and poor prognosis [25]. In the present study, we found that platelet lysates from patients after RFA accelerated HCC cell vasculogenic mimicry in vitro, which indicated tumor growth and metastasis was enhanced. 
A

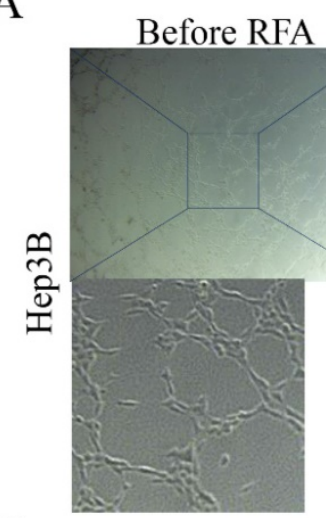

C

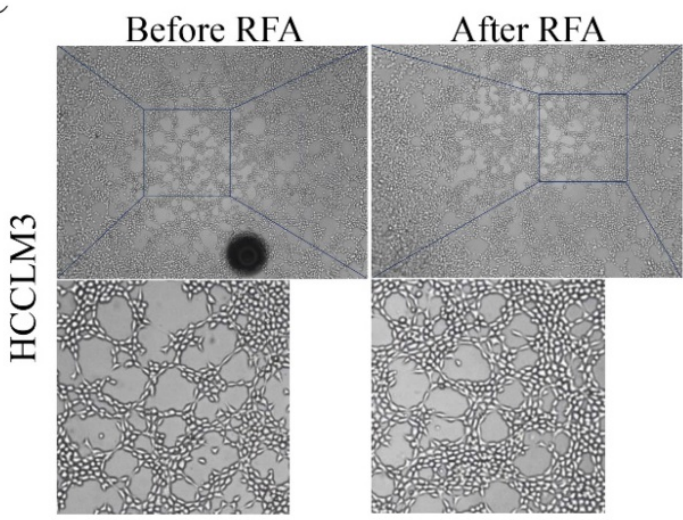

B

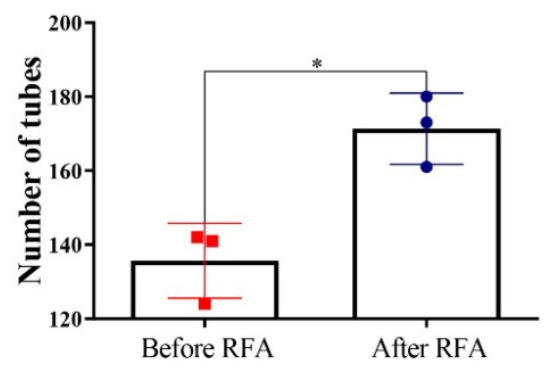

D

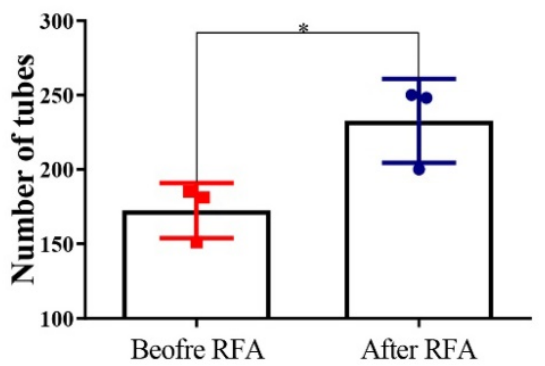

Figure 3. Platelet lysates from patients after RFA facilitate vasculogenic mimicry of HCC cells. Tube formation was performed to evaluate the effect of platelet lysates on vascular mimicry in HCC cells. (A, C) Representative in vitro capillary network formation of HCC cells treated with platelet lysates from patients before or after RFA in Hep3B and HCCLM3 cells. (B, D) Quantitative analysis of the mean number of tube-like structures formed using Image) in Hep3B and HCCLM3 cells. Data are presented as mean \pm SD. ${ }^{*} P<0.05$.

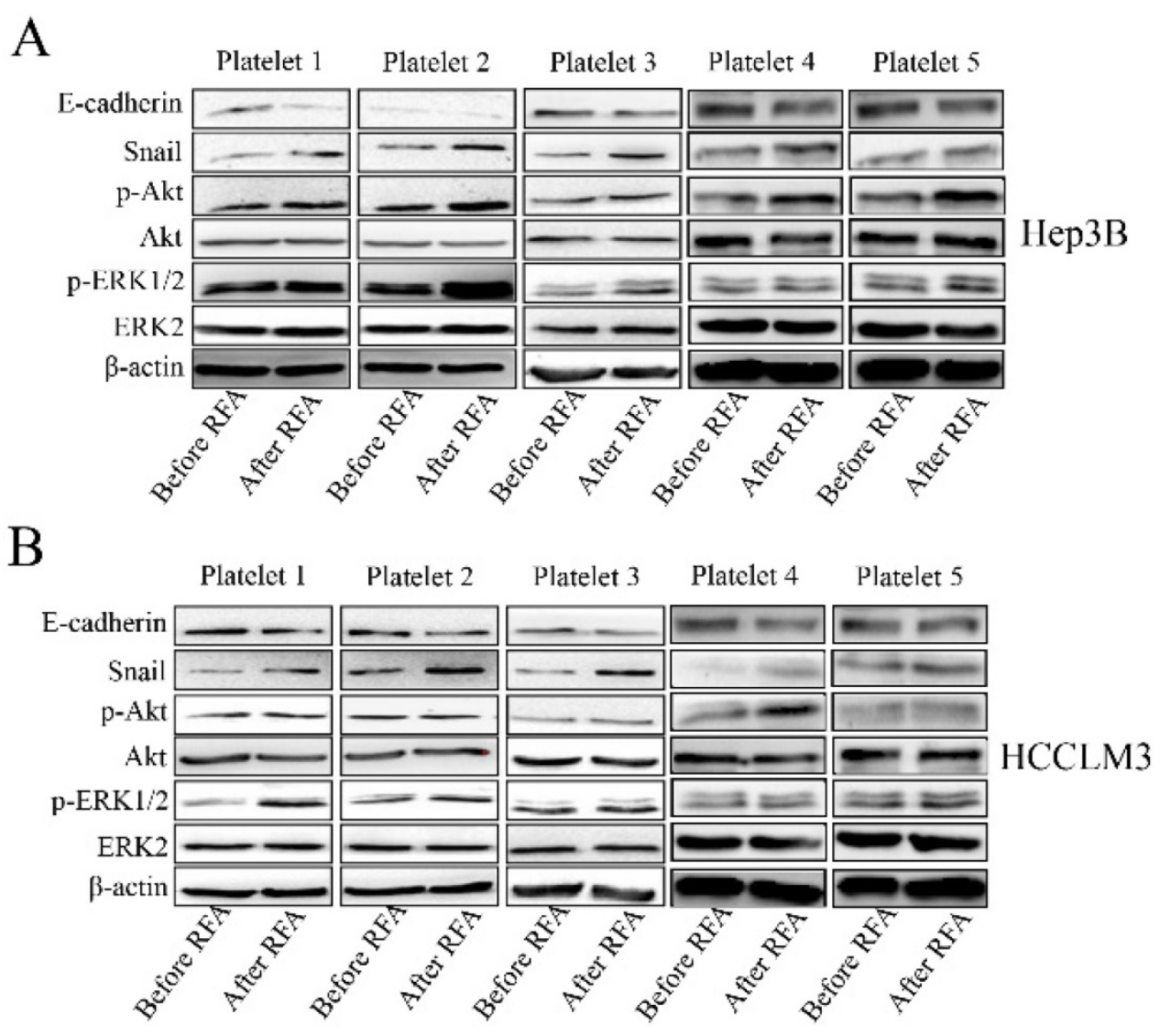




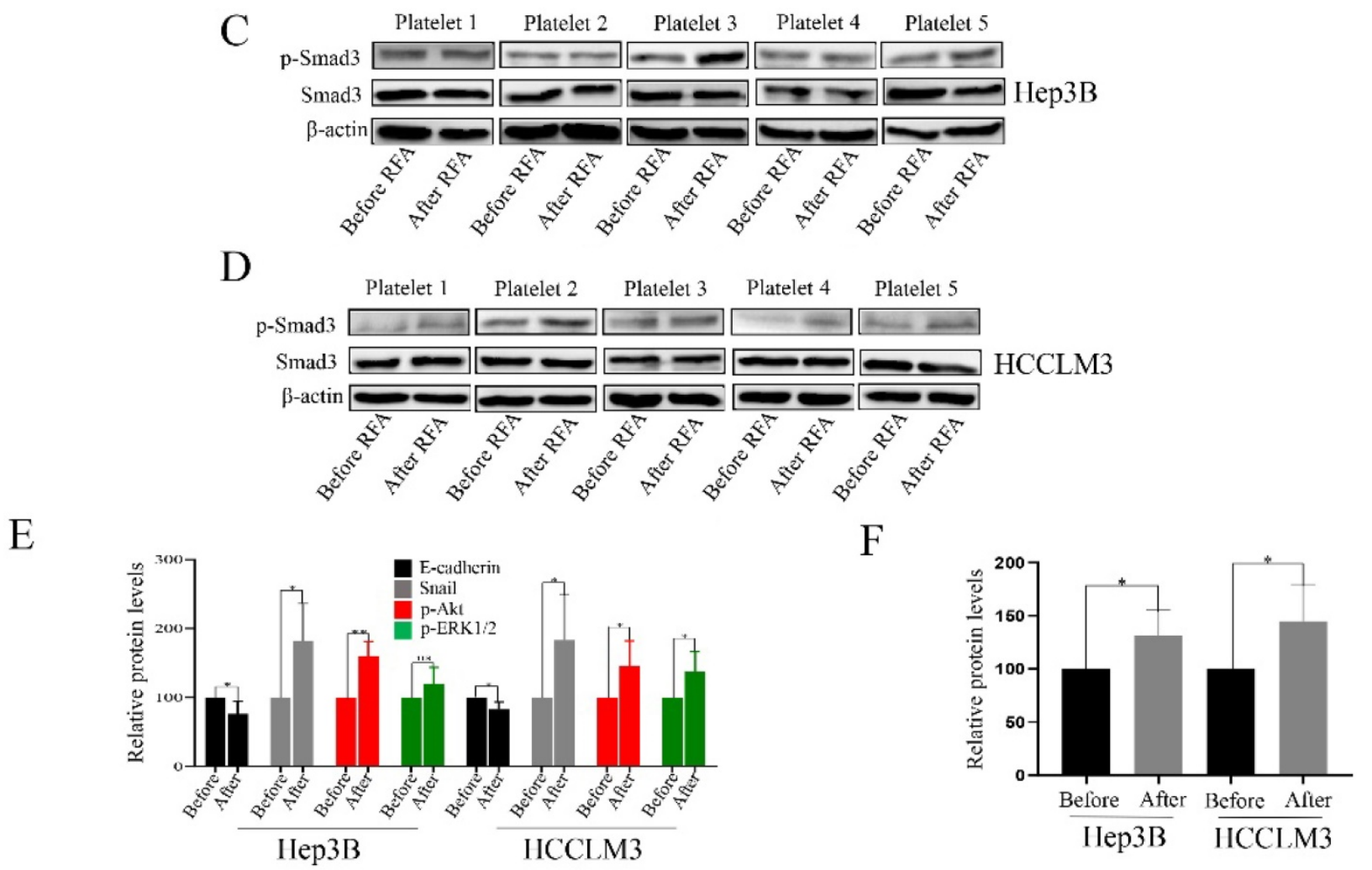

Figure 4. Platelet lysates activate the Akt, ERK1/2 and Smad3 signaling pathways in HCC cells. We also investigated the associated mechanism involved in the process. The expression of p-Akt, p-ERK1/2, snail and E-cadherin was examined in Hep3B (A) and HCCLM3 cells (B) after treatment with platelet lysates from patients before and after RFA using western blot. (C, D) The expression of p-Smad3 was examined in Hep3B and HCCLM3 cells. (E) The statistical results in the expression of E-cadherin, p-Akt, snail and p-ERK1/2 were shown. (F) The statistical results in the expression of $p$-Smad3 were shown. Data are presented as mean \pm SD. ${ }^{*} P<0.05$; ${ }^{* *} P<0.01 ;$ ns, no significance.

A
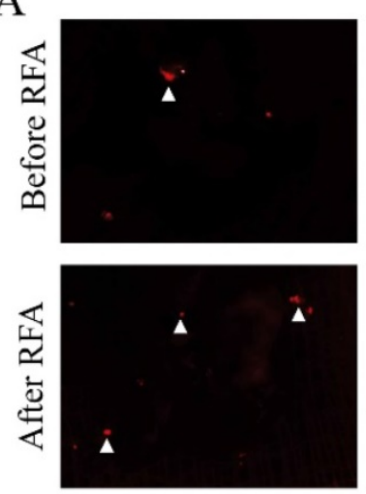

$\mathrm{B}$

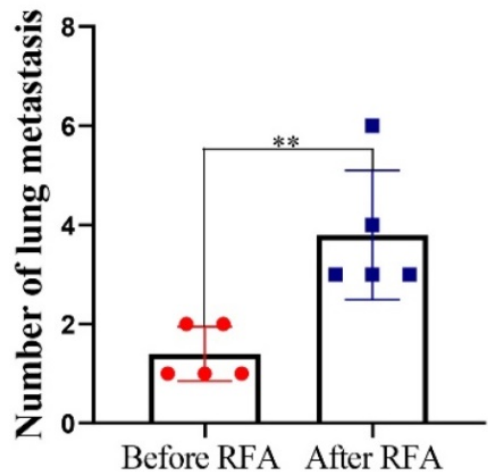

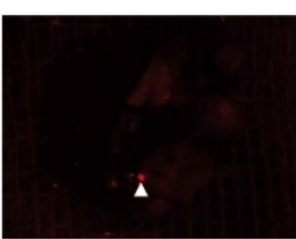
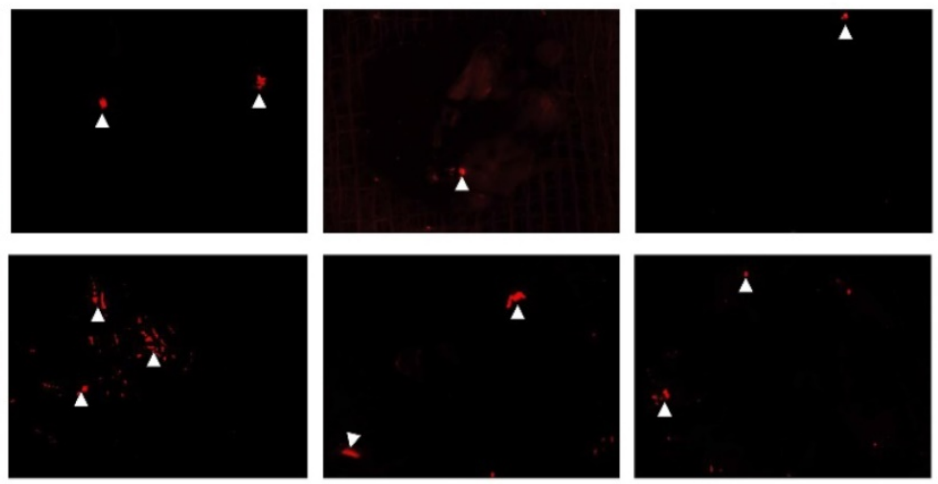

C

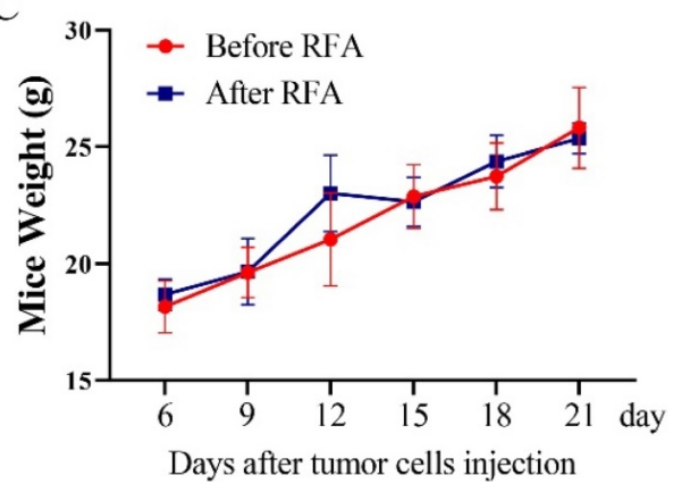

Figure 5. Platelet lysates from patients after RFA promote tumor lung metastasis. To evaluate the effect of platelet lysates on tumor metastasis, Hep3B-Luc2-tdT cells after the treatment of platelet lysates from patients before or after RFA were injected through vein tail into mice. (A) In vivo Imaging System was used to quantify metastatic nodules. Pictures of lung metastatic nodules were shown at the end of the experiment. (B) The number of lung metastatic nodules was counted. (C) Mice weight was examined every three days. Data are presented as mean $\pm S D$. ${ }^{* *} P<0.01$. 
Epithelial-mesenchymal transition is involved in the tumor metastasis and vasculogenic mimicry [26, 27]. Furthermore, Akt, ERK $1 / 2$ and Smad 3 signaling pathways participate in the epithelial-mesenchymal transition of HCC $[28,29]$. Therefore, we observe the effect of platelet lysates on those signaling, and found that platelet lysates from patients after RFA could promote epithelial-mesenchymal transition and Akt, ERK1/2 and Smad3 signaling activation, which suggested platelet lysates may facilitate tumor metastasis and vasculogenic mimicry through Akt/ERK1/2/Smad3 signaling mediating epithelialmesenchymal transition.

Anti-platelet therapy, especially for aspirin, has shown a promising chemo-preventive agent for many cancer, including colorectal cancer, esophagus cancer, gastric cancer, pancreatic cancer, breast cancer and prostate cancer [30-35]. Anti-platelet therapy has also shown protective effects against HCC in preclinical studies and reduces the risk of HCC in chronic hepatitis B [36]. Anti-platelet therapy is associated with a better prognosis of patients with hepatitis B virus-related HCC after liver resection [37]. Meanwhile, aspirin in combination with TACE could improve overall survival in patients with unresectable HCC [38]. The inverse associated between aspirin use and liver cancer was also demonstrated [39]. One study demonstrated that aspirin as an antiinflammation drug could inhibit the rapid progression of residual hepatic VX2 carcinoma following RFA [40]. However, in the study, the authors considered that inflammation induced by thermal destruction of the tumor following RFA was the key cause of rapid progression of residual tumor, and aspirin was regarded as an anti-inflammation drug. Our results found that platelet lysates could promote tumor progression in HCC after RFA, therefore aspirin maybe also play the role partly as an anti-platelet drug in the above study. All the results indicated that RFA may combine with anti-platelet drug to prevent the recurrence and metastasis of HCC in the process of RFA.

In conclusion, platelet lysates from HCC patients after RFA promoted the proliferation, migration, invasion and vasculogenic mimicry of HCC cells, which indicated that RFA in combination with antiplatelet drug may be used to improve the prognosis of HCC.

\section{Supplementary Material}

Supplementary figures and tables.

http://www.medsci.org/v17p2104s1.pdf

\section{Acknowledgements}

This work was supported by Grants 81502650 and 81572957 from the National Natural Science Foundation of China, Grant QML20190306 from Beijing Hospitals Authority Youth Program and Grant 2019 from Capital Medical University Incubating Program.

\section{Competing Interests}

The authors have declared that no competing interest exists.

\section{References}

1. Craig AJ, von Felden J, Garcia-Lezana T, Sarcognato S, Villanueva A. Tumour evolution in hepatocellular carcinoma. Nat Rev Gastroenterol Hepatol. 2020;17(3):139-52.

2. Forner A, Reig M, Bruix J. Hepatocellular carcinoma. Lancet. 2018;391 (10127):1301-14.

3. Seror O, N'Kontchou G, Nault JC, Rabahi Y, Nahon P, Ganne-Carrie N, Grando V, Zentar N, Beaugrand M, Trinchet JC, Diallo A, Sellier N. Hepatocellular Carcinoma within Milan Criteria: No-Touch Multibipolar Radiofrequency Ablation for Treatment-Long-term Results. Radiology. 2016;280 (2):611-21.

4. Xu XR, Yousef GM, Ni H. Cancer and platelet crosstalk: opportunities and challenges for aspirin and other antiplatelet agents. Blood. 2018;131 (16):1777-89.

5. Sabrkhany S, Kuijpers MJE, van Kuijk SMJ, Sanders L, Pineda S, Olde Damink SWM, Dingemans AC, Griffioen AW, Oude Egbrink MGA. A combination of platelet features allows detection of early-stage cancer. European journal of cancer. 2017;80:5-13.

6. Sabrkhany S, Griffioen AW, Oude Egbrink MG. The role of blood platelets in tumor angiogenesis. Biochimica et biophysica acta. 2011;1815 (2):189-96.

7. Quirk M, Kim YH, Saab S, Lee EW. Management of hepatocellular carcinoma with portal vein thrombosis. World journal of gastroenterology. 2015;21 (12):3462-71.

8. Foss A, Munoz-Sagredo L, Sleeman J, Thiele W. The contribution of platelets to intravascular arrest, extravasation, and outgrowth of disseminated tumor cells. Clin Exp Metastasis. 2019;37(1):47-67.

9. Plantureux L, Mege D, Crescence L, Carminita E, Robert S, Cointe S, Brouilly N, Ezzedine W, Dignat-George F, Dubois C, Panicot-Dubois L. The interaction of platelets with colorectal cancer cells inhibits tumor growth but promotes metastasis. Cancer Res. 2020;80(2):291-303.

10. Hinz S, Tepel J, Roder C, Kalthoff H, Becker T. Profile of serum factors and disseminated tumor cells before and after radiofrequency ablation compared to resection of colorectal liver metastases - a pilot study. Anticancer research. 2015;35 (5):2961-7.

11. Chudasama D, Rice A, Anikin V, Soppa G, Dalal P. Circulating Tumour Cells in Patients with Malignant Lung Tumors Undergoing Radio-frequency Ablation. Anticancer research. 2015;35 (5):2823-6.

12. Upadhyay GA, Alenghat FJ. Catheter Ablation for Atrial Fibrillation in 2019. Jama. 2019;322 (7):686-87.

13. Stazi A, Scalone G, Laurito M, Milo M, Pelargonio G, Narducci ML, Parrinello R, Figliozzi S, Bencardino G, Perna F, Lanza GA, Crea F. Effect of remote ischemic preconditioning on platelet activation and reactivity induced by ablation for atrial fibrillation. Circulation. 2014;129 (1):11-7.

14. Leblanc R, Peyruchaud O. Metastasis: new functional implications of platelets and megakaryocytes. Blood. 2016;128 (1):24-31.

15. Ferroni P, Santilli F, Cavaliere F, Simeone P, Costarelli L, Liani R, Tripaldi R, Riondino S, Roselli M, Davi G, Guadagni F. Oxidant stress as a major determinant of platelet activation in invasive breast cancer. International journal of cancer. 2017;140 (3):696-704.

16. Miyashita T, Tajima H, Makino I, Nakagawara H, Kitagawa H, Fushida S, Harmon JW, Ohta T. Metastasis-promoting role of extravasated platelet activation in tumor. The Journal of surgical research. 2015;193 (1):289-94.

17. Mitrugno A, Williams D, Kerrigan SW, Moran N. A novel and essential role for FcgammaRIIa in cancer cell-induced platelet activation. Blood. 2014;123 (2):249-60.

18. Shen $\mathrm{Y}$, Wang $\mathrm{H}$, Chen $\mathrm{X}, \mathrm{Li} \mathrm{W}$, Chen J. Prognostic significance of lymphocyte-to-monocyte ratio and platelet-to-lymphocyte ratio in patients with hepatocellular carcinoma undergoing transcatheter arterial chemoembolization and radiofrequency ablation. Onco Targets Ther. 2019;12:7129-37.

19. Alkozai EM, Porte RJ, Adelmeijer J, Zanetto A, Simioni P, Senzolo M, Lisman T. No evidence for increased platelet activation in patients with hepatitis B- or C-related cirrhosis and hepatocellular carcinoma. Thrombosis research. 2015;135 (2):292-7.

20. Sitia G, Iannacone M, Guidotti LG. Anti-platelet therapy in the prevention of hepatitis B virus-associated hepatocellular carcinoma. Journal of hepatology. 2013;59 (5):1135-8

21. Refolo MG, D'Alessandro R, Lippolis C, Messa C, Carella N, Cavallini A, Carr BI. Modulation of Doxorubicin mediated growth inhibition of hepatocellular 
carcinoma cells by platelet lysates. Anti-cancer agents in medicinal chemistry. 2014;14 (8):1154-60.

22. Carr BI, Cavallini A, D'Alessandro R, Refolo MG, Lippolis C, Mazzocca A, Messa C. Platelet extracts induce growth, migration and invasion in human hepatocellular carcinoma in vitro. BMC cancer. 2014;14:43.

23. He AD, Xie W, Song W, Ma YY, Liu G, Liang ML, Da XW, Yao GQ, Zhang BX, Gao CJ, Xiang JZ, Ming ZY. Platelet releasates promote the proliferation of hepatocellular carcinoma cells by suppressing the expression of KLF6. Scientific reports. 2017;7 (1):3989.

24. Zhang X, Zhang J, Zhou H, Fan G, Li Q. Molecular Mechanisms and Anticancer Therapeutic Strategies in Vasculogenic Mimicry. J Cancer. 2019;10 (25):6327-40.

25. Fernandez-Cortes M, Delgado-Bellido D, Oliver FJ. Vasculogenic Mimicry: Become an Endothelial Cell "But Not So Much". Front Oncol. 2019;9:803.

26. Wang HF, Wang SS, Zheng M, Dai LL, Wang K, Gao XL, Cao MX, Yu XH, Pang X, Zhang M, Wu JB, Wu JS, Yang X, Tang YJ, Chen Y, Tang YL, Liang $\mathrm{XH}$. Hypoxia promotes vasculogenic mimicry formation by vascular endothelial growth factor A mediating epithelial-mesenchymal transition in salivary adenoid cystic carcinoma. Cell Prolif. 2019;52 (3):e12600.

27. Zhang JG, Zhang DD, Liu Y, Hu JN, Zhang X, Li L, Mu W, Zhu GH, Li Q, Liu GL. RhoC/ROCK2 promotes vasculogenic mimicry formation primarily through ERK/MMPs in hepatocellular carcinoma. Biochim Biophys Acta Mol Basis Dis. 2019;1865 (6):1113-25.

28. Li Q Wang C, Wang Y, Sun L, Liu Z, Wang L, Song T, Yao Y, Liu O, Tu K. HSCs-derived COMP drives hepatocellular carcinoma progression by activating MEK/ERK and PI3K/AKT signaling pathways. J Exp Clin Cancer Res. 2018;37 (1):231.

29. Xu W, Liu H, Liu ZG, Wang HS, Zhang F, Wang H, Zhang J, Chen JJ, Huang HJ, Tan Y, Cao MT, Du J, Zhang QG, Jiang GM. Histone deacetylase inhibitors upregulate Snail via Smad2/3 phosphorylation and stabilization of Snail to promote metastasis of hepatoma cells. Cancer Lett. 2018; 420:1-13.

30. Rothwell PM, Wilson M, Elwin CE, Norrving B, Algra A, Warlow CP, Meade TW. Long-term effect of aspirin on colorectal cancer incidence and mortality: 20-year follow-up of five randomised trials. Lancet. 2010;376 (9754):1741-50.

31. Masclee GM, Coloma PM, Spaander MC, Kuipers EJ, Sturkenboom MC. NSAIDs, statins, low-dose aspirin and PPIs, and the risk of oesophageal adenocarcinoma among patients with Barrett's oesophagus: a population-based case-control study. BMJ open. 2015;5 (1):e006640.

32. Kim YI, Kim SY, Kim JH, Lee JH, Kim YW, Ryu KW, Park JH, Choi IJ. Long-Term Low-Dose Aspirin Use Reduces Gastric Cancer Incidence: A Nationwide Cohort Study. Cancer research and treatment : official journal of Korean Cancer Association. 2016;48 (2):798-805.

33. Risch HA, Lu L, Streicher SA, Wang J, Zhang W, Ni Q, Kidd MS, Yu H, Gao YT. Aspirin Use and Reduced Risk of Pancreatic Cancer. Cancer epidemiology, biomarkers \& prevention : a publication of the American Association for Cancer Research, cosponsored by the American Society of Preventive Oncology. 2017;26 (1):68-74.

34. Lu L, Shi L, Zeng J, Wen Z Aspirin as a potential modality for the chemoprevention of breast cancer: A dose-response meta-analysis of cohort studies from 857,831 participants. Oncotarget. 2017;8 (25):40389-401.

35. Cuzick J, Thorat MA, Andriole G, Brawley OW, Brown PH, Culig Z, Eeles RA, Ford LG, Hamdy FC, Holmberg L, Ilic D, Key TJ, La Vecchia C, Lilja H, Marberger M, Meyskens FL, Minasian LM, Parker C, Parnes HL, Perner S, Rittenhouse H, Schalken J, Schmid HP, Schmitz-Drager BJ, Schroder FH, Stenzl A, Tombal B, Wilt TJ, Wolk A. Prevention and early detection of prostate cancer. The Lancet. Oncology. 2014;15 (11):e484-92.

36. Lee M, Chung GE, Lee JH, Oh S, Nam JY, Chang Y, Cho H, Ahn H, Cho YY, Yoo JJ, Cho Y, Lee DH, Cho EJ, Yu SJ, Lee DH, Lee JM, Kim YJ, Yoon JH. Antiplatelet therapy and the risk of hepatocellular carcinoma in chronic hepatitis B patients on antiviral treatment. Hepatology. 2017;66(5):1556-69.

37. Lee PC, Yeh CM, Hu YW, Chen CC, Liu CJ, Su CW, Huo TI, Huang YH, Chao Y, Chen TJ, Lin HC, Wu JC. Antiplatelet Therapy is Associated with a Better Prognosis for Patients with Hepatitis B Virus-Related Hepatocellular Carcinoma after Liver Resection. Ann Surg Oncol. 2016;23 (Suppl 5):874-83.

38. Li JH, Wang Y, Xie XY, Yin X, Zhang L, Chen RX, Ren ZG. Aspirin in combination with TACE in treatment of unresectable HCC: a matched-pairs analysis. American journal of cancer research. 2016;6 (9):2109-16.

39. Petrick JL, Sahasrabuddhe VV, Chan AT, Alavanja MC, Beane-Freeman LE, Buring JE, Chen J, Chong DQ, Freedman ND, Fuchs CS, Gaziano JM, Giovannucci E, Graubard BI, Hollenbeck AR, Hou L, Jacobs EJ, King LY, Koshiol J, Lee IM, Linet MS, Palmer JR, Purdue MP, Rosenberg L, Schairer C, Sesso HD, Sigurdson AJ, Wactawski-Wende I, Zeleniuch-Jacquotte A, Campbell PT, McGlynn KA. NSAID Use and Risk of Hepatocellular Carcinoma and Intrahepatic Cholangiocarcinoma: The Liver Cancer Pooling Project. Cancer prevention research. 2015;8 (12):1156-62.

40. Jiang T, Zhang X, Ding J, Duan B, Lu S. Inflammation and cancer: inhibiting the progression of residual hepatic VX2 carcinoma by anti-inflammatory drug after incomplete radiofrequency ablation. International journal of clinical and experimental pathology. 2015;8 (11):13945-56. 